\title{
Analyzing the Evolutionary Stability for Behavior Strategies in Reverse Supply Chain
}

\author{
Daijiro Tomita, Etsuko Kusukawa* \\ Graduate School of Engineering, Osaka Prefecture University, Osaka, Japan
}

(Received: January 3, 2015 / Revised: March 11, 2015 / Accepted: March 13, 2015)

\begin{abstract}
In recent years, for the purpose of solving the problem regarding environment protection and resource saving, certain measures and policies have been promoted to establish a reverse supply chains (RSCs) with material flows from collection of used products to reuse the recycled parts in production of products. It is necessary to analyze behaviors of RSC members to determine the optimal operation. This paper discusses a RSC with a retailer and a manufacturer and verifies the behavior strategies of RSC members which may change over time in response to changes parameters related to the recycling promotion activity in RSC. A retailer takes two behaviors: cooperation/non-cooperation in recycling promotion activity. A manufacturer takes two behaviors: monitoring/non-monitoring of behaviors of the retailer. Evolutionary game theory combining the evolutionary theory of Darwin with game theory is adopted to clarify analytically evolutionary outcomes driven by a change in each behavior of RSC members over time. The evolutionary stable strategies (ESSs) for RSC members' behaviors are derived by using the replicator dynamics. The analysis numerically demonstrates how parameters of the recycling promotion activity: (i) sale promotion cost, (ii) monitoring cost, (iii) compensation and (iv) penalty cost affect the judgment of ESSs of behaviors of RSC members.
\end{abstract}

Keywords: Green Supply Chain, Game Theory, Evolutionarily Stable Strategy, Replicator Dynamics

* Corresponding Author, E-mail: kusukawa@eis.osakafu-u.ac.jp

\section{INTRODUCTION}

As the social concern regarding the environment problem is growing worldwide, the concept of a new supply chain management has been important in optimally controlling a supply chain which incorporates reverse chains/logistics into traditional forward chains/logistics. The traditional forward chains/logistics construct the flows from procurement of new materials through production of new products to sell them. The reverse chains/logistics are composed of the flows from collection of used products through recycling parts from the used products to reuse the recycled parts (Aras et al., 2004; Behret and Korugan, 2009; Ferguson et al., 2009; Fleischman et al, 1997; Guide and Wassenhove, 2001; Inderfurth, 2005; Konstantaras et al., 2010; Mukhopadhyay and Ma, 2009; Nenes et al., 2010; Pokharel and
Liang, 2012; Teunter and Flapper, 2011; Wei et al., 2011; Wu, 2012, Watanabe et al., 2013, Watanabe and Kusukawa, 2014). Also, a supply chain which organizes the forward chains and the reverse chains has been called as a closed-supply chain, a reverse supply chain or a green supply chain (Bakal and Akcali, 2006; Barari et al., 2012, Fleischman et al., 1997; Guide et al., 2003; Inderfurth, 2005; Kaya, 2010; Lee et al., 2011; Shi et al., 2010, 2011; Tagaras and Zikopoulos, 2008; Thierry et al., 1995; Van Wassenhove and Zikopoulos, 2010; Watanabe et al., 2013, Watanabe and Kusukawa, 2014, Wei et al., 2012; Yan and Sun, 2012; Zikopoulos and Tagaras, 2007, 2008). In this paper, a supply chain which has the forward chains and the reverse chains is called as a reverse supply chain (RSC). The manufacturing to reuse parts recycled from used products is called the remanufacturing. 
It is necessary to take some measures and policies in order to promote $3 \mathrm{R}$ activities (Reuse-Recycle-Reduce) in a RSC. Several previous papers have dealt with the optimal operations for a RSC, and the uncertainty in remanufacturing has been attracting more attention in recent papers. The incorporation of the uncertainty in demands of products/parts and collection quantity of used products into a RSC has been discussed by Inderfurth (2005), Lee et al. (2011), Mukhopadhyay and Ma (2009), Shi et al. (2010, 2011), and Wei et al. (2011). The incorporation of the price-sensitivity in collection quantity of used products and demands of products/parts into the optimal tactical production planning RSC has been discussed by Bakal and Akcali (2006), Pokharel and Liang (2012), Shi et al. (2010), Teunter and Flapper (2011), Wei et al. (2012), and Yan and Sun (2012). Also, the impacts of inspection and sorting of used products on the optimal production planning in a RSC have been discussed by Aras et al. (2004), Behret and Korugan (2009), Ferguson et al. (2009), Guide et al. (2003), Konstantaras et al. (2010), Nenes et al. (2010), Tagaras and Zikopoulos (2008), Van Wassenhove and Zikopoulos (2010), and Zikopoulos and Tagaras (2007, 2008).

When a RSC is operated, it is necessary to consider a variety of qualities of used products collected from either a market or customers. Some authors have discussed the optimal production planning by incorporating uncertainty in quality of used products into the RSC. Aras et al. (2004) discussed the issue of the stochastic nature of product returns and found conditions to clarify which quality-based categorization was the most cost effective. Zikopoulos and Tagaras (2007) verified how the profitability of reuse activity was affected by uncertainty regarding the quality of returned products in two collection sites and found the unique optimal solution (quantities of procurement and production). In Guide et al. (2003) and Ferguson et al. (2009), returned products were assumed to have $N$ quality categories, and the procurement prices and the remanufacturing costs were different based on the corresponding quality level. Behret and Korugan (2009) discussed a remanufacturing stage with uncertainties in qualities of remanufacturing products, return rates, and return times of returned products. After returned products were classified under the uncertainty in quality, remanufacturing processing times, material recovery rates, the remanufacturing costs, and disposal costs were optimized by using the ARENA simulation program. Mukhopadhyay and Ma (2009) discussed a RSC which consists of a retailer who sold a single products and a manufacturer who collected used products from a market, remanufactured a single parts from the used products and then produced a single products. Here, two situations were assumed for the remanufacturing ratio between reuse parts and used products: a constant situation and an uncertain situation. Under each situation, the optimal production strategy was proposed for the procurement quantity of the used products, the remanufacturing quantity of parts from the used products and the production quantity of new parts from new materials. Nenes et al. (2010) reported that both quality and quantity of returns (used products) were unfortunately highly stochastic, and found the optimal policy for the order quantity of a single new products and the remanufacturing quantity of a single products so as to optimize the companies' performance, such as minimizing the companies' expected cost or maximizing the companies' expected profit. Teunter and Flapper (2011) verified how quality of cores (i.e., products supplied for remanufacturing) could vary significantly, affecting the cost of remanufacturing, and derived the optimal policies for acquisition and remanufacturing for both deterministic and uncertain demand. Kaya (2010) focused on a RSC which consisted of a retailer who collected used products from customers and sold a single products and a manufacturer who remanufactured parts from the used products and produced the products. The optimal decisions were proposed for collection incentive of used products and production quantities of both remanufacturing parts and new parts.

Also, it is necessary to decide the optimal operations to establish a RSC in order to obtain its profitability. In a decentralized RSC, members in the RSC decide the optimal operations to maximize their profits. As one of the optimal decision-making approaches under a decentralized RSC, the Stackelberg game has been adopted in several previous papers. In the Stackelberg game, there is a single leader of the decision-making and a single (multiple) follower (s) of the decision-making of the leader. The leader of the decision-making determines the optimal strategy so as to maximize the leader's (expected) profit. The follower(s) of the decision-making determine(s) the optimal strategy so as to maximize the follower(s)'s (expected) profit under the optimal strategy determined by the leader of the decision-making (Aust and Buscher, 2012; Berr, 2011; Cachon and Netessine, 2004; Cai et al., 2009; Esmaeili and Zeephongsekul, 2010; Hu et al., 2011; Lee et al., 2011; Leng and Parlar, 2009; Liu et al., 2012; Mukhopadhyay et al., 2011; Xu et al., 2012; Yan and Sun, 2012).

Here, in supply chain management, the optimal decision under an integrated supply chain maximizing the whole supply chain's expected profit can bring the more expected profit to the whole supply chain than that under a decentralized supply chain maximizing the expected profit of each member in a supply chain. So, from the aspect of the total optimization in supply chain management, it is preferable for all members in a supply chain to shift the optimal decision under an integrated supply chain. However, note that it is the absolute requirement for all members under an integrated supply chain to bring the more expected profits to all of them than those under a decentralized supply chain. For the purposed of achievement of the increases in profits of all members under an integrated supply chain, a variety of supply chain coordination approaches between all members in a supply chain have been discussed by Cachon and Netessine (2004), Du et al. (2011), Kaya (2010), Tsay et al. (1999), Wei et al. (2012), Wu (2012), Yan 
and Sun (2012), and Yano and Gilbert (2004).

The incorporation of the game theory into not only the optimal pricing strategy, but also the supply chain coordination in a RSC has been discussed by Du et al. (2011), Kaya (2010), Wei et al. (2012), Wu (2012), and Yan and Sun (2012). Here, it is necessary to analyze members' behaviors in both a supply chain (SC) and a RSC to determine the optimal operation for those SCs. In general, the game theory is used to analyze members' behaviors in both a supply chain (SC) and a RSC. The orthodox game theory usually assumes that members in a SC/RSC can share correctly the following information: (i) each other's defined rule of game; (ii) common and full knowledge of rationality; (iii) the preference of each other's behavior; (iv) the optimal action of each other under rational situation.

However, in reality, all assumptions mentioned above may not be held between members in a SC/RSC (Zhou and Deng, 2006; Zhu and Dou, 2007; Yu et al., 2009; Xiao and Chen, 2009; Barari, et al., 2012). The behavior strategies of members in a SC/RSC may change over time due to changes of members' situations such as cost parameters and the quantities of their transactions (Zhou and Deng, 2006; Zhu and Dou, 2007; Yu et al., 2009; Xiao and Chen, 2009; Barari, et al., 2012). Under above situations, the evolutionary game theory, which combines the evolutionary theory by Darwin with the game theory, has become a powerful integrated tool to analyze the evolutionary processes/members' outcomes which are driven by changes in members' behaviors.

Regarding a SC, some previous papers have dealt with applications of the evolutionary game theory into the analysis of members' behaviors in a SC. Zhou and Deng (2006) discussed an asymmetric model of the evolutionary game between a retailer and a manufacturer with the asymmetric information regarding the retailer's sales promotion of products. The evolutionary stable strategies of the asymmetric model were obtained, using the replicator dynamic mechanism. Also, the different evolutionary stable strategies were analyzed by changing the values of system parameters in a SC. Yu et al. (2009) discussed a VMI supply chain consisting of an upstream supplier and a downstream buyer, and showed how to analyze the intrinsic evolutionary mechanism of the VMI supply chain by applying the evolutionary game theory with the replicator dynamic equation. The impact of system parameters in a SC without and with VMI on the evaluation of the evolutionary stable strategies was examined.

Regarding a RSC, some previous papers have dealt with applications of the evolutionary game theory into the analysis of members' behaviors in a RSC. Zhu and Dou (2007) discussed reverse supply chains (RSCs) consisting of governments and core enterprises, studied the game relationships between governments and core enterprises in RSCs. The respective costs and the respective benefits between them without and with the recycling activity in a RSC were analyzed, and estab- lished an evolutionary game model in the RSC. Different equilibrium results for the evolutionary game model were analyzed, and explored win-win ways between governments and core enterprises in RSCs. Here, the promotion activity to recycle the used products in a RSC is referred simply to the recycling promotion activity. However, neither the recycling promotion activity nor the cooperation of the recycling promotion activity between governments and core enterprises were discussed. The effects of the recycling promotion activity on both the collection quantity of used products and the product demand were not discussed. This previous study focused on only entities' costs and entities' incomes related to the recycling activity in a RSC. So, unless any recycling activity was operated, all entities' costs and entities' benefits resulted in 0. Barari et al. (2012) discussed a case study regarding a RSC consisting of one producer and one retailer, and verified the synergetic alliance between the environmental and commercial benefits by establishing coordination in the RSC by using evolutionary dynamics. Green financial burden sharing contract was considered between the producer and the consumer in the RSC. The degree of sales effort of products were considered for the retailer. The actual costs related to the recycling activity in the RSC were combined with the objective of the profit maximization for the entities in the RSC by using the evolutionary dynamics. Using the replicator dynamics equation, the equilibrium point was found by not only balancing the price with the green benefits of products, but also maximizing the entities' profit in the RSC. However, in this previous study, formulations of costs, incomes and profits related to entities with the recycling activity in a RSC were specialized as the conceptual framework for a case study regarding a specified RSC, and the property of the specified RSC was verified analytically by using the evolutionary dynamics.

Differently from the previous papers mentioned above, this paper focuses on the following issues: (1) Analysis of a RSC using the evolutionary dynamics and presentation of the evolutionary stable strategies (EESs) for behavior strategies of members in the RSC, (2) Analysis of the cooperation of the recycling promotion activity between members in the RSC by using concepts of compensation and penalty, (3) Analysis of the effect of the recycling promotion activity on both the collection quantity of used products and the product demand, (4) Formulations and analysis of the evolutionary dynamics by using costs, incomes and profits related to members in the RSC in mathematical expressions as to both without/with and monitoring/non-monitoring the recycling promotion activity in behavior strategies of members in the RSC.

This paper focuses on the optimal operation for a RSC to encourage to collect and recycle a single type of used products, such as consumer electronics (mobile phone, personal computer), semiconductor and electronic component (Guide, 2000; Guide and Jayaraman, 2000; 
Guide and Van Wassenhove, 2001; Guide et al., 2003; Ferguson et al., 2009) under the uncertainties in product demand and quality of used products collected from customers. Concretely, this paper discusses a reverse supply chain (RSC) consisting of a retailer and a manufacturer as RSC members. In a RSC, the retailer hands the used products collected from customers over to a manufacturer. In this case, the retailer places an order for an order quantity of a single products to the manufacturer, corresponding to the product demand. Here, in this paper, the promotion activity to recycle the used products in a RSC is referred simply to the recycling promotion activity. A retailer takes one of the own two behavior strategies: [behavior strategy 1] cooperation in two types of the recycling promotion activity: (i) collection promotion activity of used products by paying an incentive to customers and (ii) sales promotion activity of the products including those reusing parts recycled from the used products or no collection promotion, [behavior strategy 2] non-cooperation in the recycling promotion activity. A manufacturer disassembles the used products, remanufactures a single parts and produces a single products reusing the recycled parts at a recycling rate and pays the compensation as a part of the retailer's incentive for collection of the used products based on the quantity of the recycled parts to the retailer. Here, the manufacturer takes one of the own two behavior strategies: [behavior strategy 1] monitoring of the retailer's the recycling promotion activity, [behavior strategy 2] non-monitoring of the retailer's the recycling promotion activity. Under the system operation of the RSC, this paper verifies the behavior strategies of members in the RSC. Here, the behavior strategies of RSC members may change over time in response to changes system parameters related to the recycling promotion activity in the RSC: (i) sale promotion cost, (ii) monitoring cost, (iii) compensation and (iv) penalty cost. The evolutionary game theory is adopted to clarify analytically the evolutionary outcomes driven by changes in members' behaviors in the RSC over time. The evolutionary stable strategies (ESSs) for RSC members' behaviors are derived by using the replicator dynamics. The analysis numerically verifies how four parameters related to the recycling promotion activity in the RSC, (i) sale promotion cost, (ii) monitoring cost, (iii) compensation and (iv) penalty cost, affect the judgment of ESSs of the behavior strategies of a retailer and a manufacturer in the RSC. The different ESSs for behavior strategies of both members in the RSC are analyzed by using the replicator dynamics through computer computation.

The contribution of this paper is to provide the behavior strategies of members in a RSC analytically by using the evolutionary game theory, which combines the evolutionary theory by Darwin based on the replicator dynamics with the game theory. It is expected that the analytical outcomes in this paper can help to verify the behavior strategies of members in a RSC even if the behavior strategies of members in a RSC may change over time due to changes of members' situations such as cost parameters and the quantities of their transactions. Also, the analytical results are to provide (1) the optimal setting regarding parameters related to the recycling promotion activity in a RSC such as (i) sale promotion cost, (ii) monitoring cost, (iii) compensation and (iv) penalty cost, (2) the practices to construct and operate a RSC profitably and (3) the informative motivations for researchers and policymakers to manage a RSC profitably.

The rest of this paper is organized as follows: in Section 2, notation used here is defined. In Section 3, model descriptions: operational flows of a RSC and behavior strategies of a retailer and a manufacturer in a RSC are described. Section 4 formulates profits of members as to their behavior strategies in a RSC. Section 5 analyzes behavior strategies of members in a RSC by applying the evolutionary game theory based on the replicator dynamics into members' behavior analysis in a RSC. Section 6 shows the results of numerical analysis of the behavior strategies of members in a RSC by using the evolutionary game theory to illustrate managerial insights for the optimal operation of the RSC addressed in this paper. In Section 7, conclusions, managerial insights and future researches for this paper are summarized.

\section{NOTATION}

- Behavior strategies of a retailer and a manufacturer

$R_{1}$ : cooperation in recycling promotion activity

$R_{2}$ : non-cooperation in recycling promotion activity

$M_{1}$ : monitoring of retailer's recycling promotion activity

$M_{2}$ : non-monitoring of retailer's recycling promotion activity

- System parameters in a RSC

$A$ : potential quantity of used products collected from customers

$t$ : the unit collection promotion cost (collection incentive) of used product when $R_{1}$ is taken by a retailer

$t_{0} \quad$ : the unit collection promotion cost (collection incentive) of used product when $R_{2}$ is taken by a retailer

$\beta_{1}$ : the correct increasing rate of collection quantity of used products when behavior strategy $\left(R_{1}\right.$, $M_{1}$ ) is taken by RSC members

$\beta_{2}$ : the estimated increasing rate of collection quantity of used products when behavior strategy $\left(R_{1}, M_{2}\right)$ is taken RSC members $\left(\beta_{2}<\beta_{1}\right)$

$r \quad$ : recycling rate to recycle a single parts from used products

$D$ : potential product demand in a market

$\alpha_{1}$ : the correct increasing rate of product demand when behavior strategy $\left(R_{1}, M_{1}\right)$ is taken by RSC members 
$\alpha_{2}$ : the estimated increasing rate of product demand when behavior strategy $\left(R_{1}, M_{2}\right)$ is taken by RSC members $\left(\alpha_{2}<\alpha_{1}\right)$

$c_{s p}:$ sales promotion cost

$c_{s}$ : monitoring cost

$R$ : compensation per used product paid to a retailer from a manufacturer for the quantity of used products to recycle parts when $R_{1}$ is taken by a retailer

$R_{0}$ : compensation per used product paid to a retailer from a manufacturer for the quantity of used products to recycle parts when $R_{2}$ is taken by a retailer

$c_{p}$ : penalty cost which a retailer pays to a manufacturer when behavior strategy $\left(R_{2}, M_{1}\right)$ is taken by members in a RSC

$p \quad$ : the unit sales price of a single products

$c_{t} \quad$ : the unit delivery cost of used products

$w$ : the unit wholesale price of a single products

$c$ : the unit production cost of a single products

$c_{a}$ : disassembly and inspection cost per used product

$c_{r}$ : the unit remanufacturing cost to produce a single parts from recyclable parts in used products

$c_{d}:$ the unit disposal cost of un-recycled parts

$c_{n}$ : the unit production cost of a single new parts

\section{MODEL DESCRIPTIONS}

\subsection{Operational Flows of a RSC}

A reverse supply chain (RSC) with a retailer and a manufacturer is considered. Also, it is assumed that a single products such as consumer electronics (mobile phone, personal computer) is produced and is sold in a market. Figure 1 shows the following operational flows of a RSC:

(I) A retailer decides either to promote or not to promote the collection of used products from customers. The retailer collects used products from customers as to the own behavior strategy, and delivers the collection quantity of the used products at the unit $\cos c_{t}$ to the manufacturer. Also, the retailer places an order with the manufacturer for a single products $D$. Here, it is assumed that the collection quantity of used products for the unit collection inventive is smaller than the retailer's order quantity $D$.

(II) The manufacturer disassembles the used products, and inspects their quality at the unit cost $c_{a}$. After that, the manufacturer remanufactures some of the recyclable parts at unit cost $c_{r}$ at a recycling rate $r$. All the un-recycled parts are disposed at the unit $\operatorname{cost} c_{d}$.

(III) The manufacturer produces the required quantity of new parts at the unit cost $c_{n}$ if the quantity of the recycled parts is unsatisfied with the required quantity of parts for the order quantity of products $D$.
( IV ) Production and wholesale of ordered products

(VI) Decision for monitoring of

(V) - Decision for sales promotion of product reusing recycled parts

- Sales of product retailer's recycling promotion activity

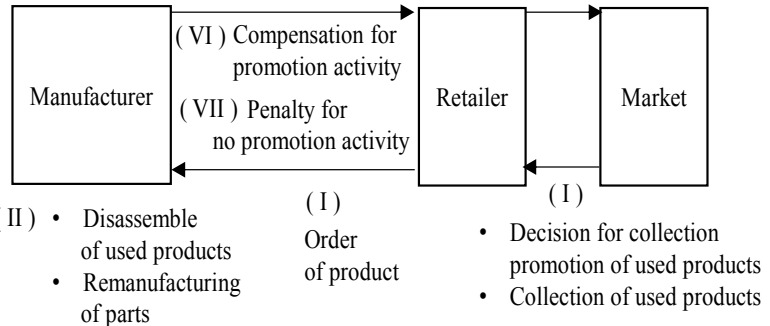

( III ) Production of new parts if necessary

Figure 1. Operational flows of a RSC.

(IV) The manufacturer produces the order quantity of products $D$ at the unit $\operatorname{cost} c$, and sells them to retailer at the unit wholesale price $w$.

(V) The retailer decides either to promote or not to promote sale of products reusing the recycled parts at the cost $c_{s p}$. Also, the retailer sells the products in a market with the unit sales price $p$ during a single period, satisfying the product demand as to the own behavior strategy.

(VI) The manufacturer decides either to monitor or not to monitor whether the retailer cooperated the recycling promotion activity or not. The manufacturer gives a compensation to the retailer for the retailer's collection incentive as to not only the own decision for monitoring, but also the retailer's action.

(VII) The retailer pays a penalty to the manufacturer when the retailer does not cooperate the recycling promotion activity and the manufacturer monitors the retailer's action without cooperation of the promotion activity.

\subsection{Behavior Strategies of Members in a RSC}

This paper assumes that both a retailer and a manufacturer have two behavior strategies regarding the recycling promotion activity of the used products. This paper defines the recycling promotion activity of used products as both the collection promotion of the used products and the sales promotion of products reusing parts recycled from used products.

A retailer takes the following two behavior strategies: $R_{1}$ : cooperation in the recycling promotion activity $R_{2}$ : non-cooperation in the recycling promotion activity.

Meanwhile, a manufacturer takes the following two behavior strategies:

$M_{1}$ : monitoring of the retailer's recycling promotion activity

$M_{2}$ : non-monitoring of the retailer's recycling promotion activity 
Table 1. Effects of behavior strategies of a retailer and a manufacturer in a RSC on collection quantity of used products, product demand and members' costs

\begin{tabular}{lcccc}
\hline \multirow{2}{*}{ Effects } & \multicolumn{5}{c}{ Behavior strategies of members in RSC } \\
\cline { 2 - 5 } & $\left(R_{1}, M_{1}\right)$ & $\left(R_{1}, M_{2}\right)$ & $\left(R_{2}, M_{1}\right)$ & $\left(R_{2}, M_{2}\right)$ \\
\hline Collection quantity & $\beta_{1} A$ & $\beta_{2} A$ & $A$ & $A$ \\
\hline Product demand & $\alpha_{1} D$ & $\alpha_{2} D$ & $D$ & $D$ \\
\hline Monitoring cost & $c_{s}$ & 0 & $c_{s}$ & 0 \\
\hline Collection cost & $t$ & $t$ & $R_{0}$ & $R_{0}$ \\
\hline Sales promotion cost & $c_{s p}$ & $c_{s p}$ & 0 & 0 \\
\hline Compensation & $R$ & $R$ & $R_{0}$ & $R_{0}$ \\
\hline Penalty & $c_{p}$ & 0 & $c_{p}$ & 0 \\
\hline
\end{tabular}

This paper refers to the behavior strategy of each member as just $(i, j)\left(i=R_{1}, R_{2}, j=M_{1}, M_{2}\right)$. Table 1 shows the effects of the behavior strategies of a retailer and a manufacturer in a RSC on the collection quantity of used products, product demand and their costs, based on the operational flows of a RSC mentioned above and in Figure 1.

\section{PROFITS OF A RETAILER AND A MANUFACTURER AS TO THEIR BEHAVIOR STRATEGIES IN A RSC}

Profits of a retailer and a manufacturer in a RSC are formulated as to their behavior strategies. Table 2 shows a payoff matrix between a retailer and a manufacturer in a RSC as to their behavior strategies and adoption ratios of their behavior strategies.

$\left(\pi_{R}, \pi_{M}\right)$ indicates profits of a retailer and a manu-

$\left(R_{1}, M_{1}\right)\left(R_{1}, M_{1}\right)$ facturer in behavior strategy $\left(R_{1}, M_{1}\right)$.

$\left(\pi_{R}, \pi_{M}\right)$ indicates profits of a retailer and a manu-

$\left(R_{1}, M_{2}\right)\left(R_{1}, M_{2}\right)$ facturer in behavior strategy $\left(R_{1}, M_{2}\right)$.

$\left(\pi_{R}, \pi_{M}\right)$ indicates profits of a retailer and a manu-

$\left(R_{2}, M_{1}\right)\left(R_{2}, M_{1}\right)$ facturer in behavior strategy $\left(R_{2}, M_{1}\right)$.

$\left(\pi_{R}, \pi_{M}\right)$ indicates profits of a retailer and a manu-

$\left(R_{2}, M_{2}\right)\left(R_{2}, M_{2}\right)$ facturer in behavior strategy $\left(R_{2}, M_{2}\right)$.

Here, denote $x$ as the adoption ratio of the retailer's population taking the behavior strategy $R_{1},(1-x)$ as that the behavior strategy $R_{2}$. Meanwhile, denote $y$ as the adoption ratio of the manufacturer's population taking the behavior strategy $M_{1},(1-y)$ as that the behavior strategy $M_{2}$. In behavior strategies between a retailer and a manufacturer in a RSC, the retailer does not know which behavior strategy the manufacturer will take before the retailer takes the own behavior strategy and vice versa.

The objective of this paper is to obtain the asymptotic stability of an equilibrium strategy pair regarding $x$ and $y$, referred to the evolutionary stable strategy (ESS). When ESS regarding $x$ and $y$ is obtained, the asymptotic
Table 2. Payoff matrix between a retailer and a manufacturer in a RSC as to their behavior strategies and adoption ratios of their behavior strategies

\begin{tabular}{|c|c|c|}
\hline Manufacturer & $\begin{array}{c}\text { Monitoring: } \\
\qquad M_{1} \\
\text { Adoption ratio : } y\end{array}$ & $\begin{array}{l}\text { Non- monitoring: } \\
\qquad M_{2} \\
\text { Adoption ratio : } 1-y\end{array}$ \\
\hline $\begin{array}{c}\text { Cooperation: } \\
R_{1} \\
\text { Adoption ratio: } x\end{array}$ & $\underset{\left(R_{1}, M_{1}\right)}{\left(\pi_{R}, R_{1}, M_{1}\right)}$ & $\underset{\left(R_{1}, M_{2}\right)}{\left(\pi_{R}, \pi_{M}, M_{2}\right)}$ \\
\hline $\begin{array}{l}\text { Non-cooperation: } \\
\qquad R_{2} \\
\text { Adoption ratio: } 1-x\end{array}$ & $\underset{\left(R_{2}, M_{1}\right)}{\left(\pi_{R}, \pi_{M}, M_{1}\right)}$ & $\underset{\left(R_{2}, M_{2}\right)}{\left.\pi_{R}, \pi_{\left(R_{2}, M_{2}\right)}\right)}$ \\
\hline
\end{tabular}

stability of an equilibrium strategy pair regarding (1-x) and $(1-y)$ can be calculated simultaneously.

- Profits of members in behavior strategy $\left(R_{1}, M_{1}\right)$

Based on Subsections 3.1 and 3.2 and Table 1, the profit of a retailer in $\left(R_{1}, M_{1}\right), \underset{\left(R_{1}, M_{1}\right)}{\pi_{R},}$, consists of the collection incentive of used products from customers, the delivery cost of used products, the procurement cost of products, the sales of products, the sales promotion cost and the compensation income from a manufacturer. $\pi_{R}$

is formulated as

$$
\underset{\left(R_{1}, M_{1}\right)}{\pi_{R}}=-t \beta_{1} A-c_{t} \beta_{1} A-w \alpha_{1} D+p \alpha_{1} D-c_{s p}+R \beta_{1} A r .
$$

Based on Subsections 3.1 and 3.2 and Table 1, the profit of a manufacturer in $\left(R_{1}, M_{1}\right), \underset{\left(R_{1}, M_{1}\right)}{\pi_{M}}$, consists of the costs regarding disassembly and inspection of used products, the remanufacturing cost of parts, the production cost of new parts, the disposal cost of un-recycled parts, the production cost of products, the wholesale of products, the compensation cost and the monitoring cost of the retailer's act. $\underset{\substack{\left(R_{1}, M_{1}\right) \\ \pi_{M}}}{\pi_{1}}$ is formulated as

$$
\begin{aligned}
\underset{\left(R_{1}, M_{1}\right)}{\pi_{M}}= & -c_{a} \beta_{1} A-c_{r} \beta_{1} A r-c_{n}\left(\alpha_{1} D-\beta_{1} A r\right)-c_{d} \beta_{1} A(1-r) \\
& -c \alpha_{1} D+w \alpha_{1} D-R \beta_{1} A r-c_{s} .
\end{aligned}
$$

- Profits of members in behavior strategy $\left(R_{1}, M_{2}\right)$

Based on Subsections 3.1 and 3.2 and Table 1, the profit of a retailer in $\left(R_{1}, M_{2}\right), \underset{\left(R_{1}, M_{2}\right)}{\pi_{R}}$, consists of the collection incentive of used products from customers, the delivery cost of used products, the procurement cost of products, the sales of products, the sales promotion cost and the compensation income from a manufacturer. $\underset{\left(R_{1}, M_{2}\right)}{\pi_{R}}$ is formulated as

$$
\underset{\left(R_{1}, M_{2}\right)}{\pi_{R}}=-t \beta_{2} A-c_{t} \beta_{2} A-w \alpha_{2} D+p \alpha_{2} D-c_{s p}+R \beta_{2} A r
$$


Based on Subsections 3.1 and 3.2 and Table 1, the profit of a manufacturer in $\left(R_{1}, M_{2}\right), \underset{\left(R_{1}, M_{2}\right)}{\pi_{M}}$, consists of the costs regarding disassembly and inspection of used products, the remanufacturing cost of parts, the production cost of new parts, the disposal cost of un-recycled parts, the production cost of products, the wholesale of products and the compensation cost. $\underset{\left(R_{1}, M_{2}\right)}{\pi_{M}}$ is formulated as

$$
\begin{aligned}
\underset{\left(R_{1}, M_{2}\right)}{\pi_{M}}= & -c_{a} \beta_{2} A-c_{r} \beta_{2} A r-c_{n}\left(\alpha_{2} D-\beta_{2} A r\right)-c_{d} \beta_{2} A(1-r) \\
& -c \alpha_{2} D+w \alpha_{2} D-R \beta_{2} A r .
\end{aligned}
$$

- Profits of members in behavior strategy $\left(R_{2}, M_{1}\right)$

Based on Subsections 3.1 and 3.2 and Table 1, the profit of a retailer in $\left(R_{2}, M_{1}\right), \underset{\left(R_{2}, M_{1}\right)}{\pi_{R}}$, consists of the collection incentive of used products from customers, the delivery cost of used products, the procurement cost of products, the sales of products, the compensation income from a manufacturer and the penalty cost to a manufacturer. $\underset{\left(R_{2}, M_{1}\right)}{\pi_{R}}$ is formulated as

$$
\underset{\left(R_{2}, M_{1}\right)}{\pi_{R}}=-t_{0} A-c_{t} A-w D+p D+R_{0} A r-c_{p} .
$$

Based on Subsections 3.1 and 3.2 and Table 1, the profit of a manufacturer in $\left(R_{2}, M_{1}\right), \underset{\left(R_{2}, M_{1}\right)}{\pi_{M}}$, consists of the costs regarding disassembly and inspection of used products, the remanufacturing cost of parts, the production cost of new parts, the disposal cost of un-recycled parts, the production cost of products, the wholesale of products, the compensation cost, the monitoring cost of the retailer's act and the penalty income from a retailer. $\pi_{M}$ is formulated as

$$
\begin{aligned}
\underset{\left(R_{2}, M_{1}\right)}{\pi_{M}}= & -c_{a} A-c_{r} A r-c_{n}(D-A r)-c_{d} A(1-r) \\
& -c D+w D-R_{0} A r-c_{s}+c_{p} .
\end{aligned}
$$

- Profits of members in behavior strategy $\left(R_{2}, M_{2}\right)$

Based on Subsections 3.1 and 3.2 and Table 1, the profit of a retailer in $\left(R_{2}, M_{2}\right), \underset{\left(R_{2}, M_{2}\right)}{\pi_{R}}$, consists of the collection incentive of used products from customers, the delivery cost of used products, the procurement cost of products, the sales of products and the compensation income from a manufacturer. $\underset{\left(R_{2}, M_{2}\right)}{\pi_{R}}$ is formulated as

$$
\underset{\left(R_{2}, M_{2}\right)}{\pi_{R}}=-t_{0} A-c_{t} A-w D+p D+R_{0} A r .
$$

Based on Subsections 3.1 and 3.2 and Table 1, the profit of a manufacturer in $\left(R_{2}, M_{2}\right), \underset{\left(R_{2}, M_{2}\right)}{\pi_{M}}$, consists of the costs regarding disassembly and inspection of used products, the remanufacturing cost of parts, the production cost of new parts, the disposal cost of un-recycled parts, the production cost of products, the wholesale of products and the compensation cost. $\pi_{M}$ is formulated as

$$
\begin{aligned}
\underset{\left(R_{2}, M_{2}\right)}{\pi_{M}}= & -c_{a} A-c_{r} A r-c_{n}(D-A r)-c_{d} A(1-r) \\
& -c D+w D-R_{0} A r .
\end{aligned}
$$

\section{ANALYZING BEHAVIOR STRATEGIES APPLYING THE EVOLUTIONARY GAME THEORY}

In behavior strategies between a retailer and a manufacturer in a RSC, the retailer does not know which behavior strategy the manufacturer will take before the retailer takes the own behavior strategy and vice versa. Also, members' behavior strategies in the RSC may change over time when members' situations, such as cost parameters and the quantities of their transactions, change. Under above situations, the evolutionary game theory can shed light on the evolutionary mechanism of a RSC in this paper, and can examine the trend of the evolutionary stability for members' behavior strategies in the RSC from a time-based perspective.

This paper uses the evolutionary game theory to analyze behavior strategies of a retailer and a manufacturer in a RSC addressed in this paper, and verify the evolutionary stabilities of members in the RSC. The evolutionary game theory combines the evolutionary theory by Darwin with the game theory. Concretely, the evolutionary game theory combines the static feature of an evolutionary stable strategy (ESS) with the dynamic nature based on the replicator dynamic mechanism (Maynard-Smith, 1974; Taylor and Jonker, 1978; Zhou and Deng, 2006; Zhu and Dou, 2007; Yu et al., 2009; Barari, et al., 2012). Using the replicator dynamics, the behavior strategies of one member of the retailer' population and one member of the manufacturer' population are analyzed by time unit (Zhou and Deng, 2006; Zhu and Dou, 2007; Yu et al., 2009; Barari, et al., 2012).

As described in Section 4 and Table 2, $x$ is the adoption ratio of the retailer's population taking the behavior strategy $R_{1},(1-x)$ is that taking the behavior strategy $R_{2}$. Also, $y$ is the adoption ratio of the manufacturer's population taking the behavior strategy $M_{1},(1-y)$ is that tasking the behavior strategy $M_{2}$. Under those situations, the expected profits for one retailer in retailer's population and one manufacturer in manufacturer's population are formulated by using Table 2 .

The expected profit of one retailer choosing the behavior strategy $R_{1}$ under the manufacturer's behavior 
strategies $M_{1}$ and $M_{2}$ is obtained as

$$
\left.E_{R 1}=\underset{\left(R_{1} \cdot M_{1}\right)}{\pi_{R}} y+\underset{\left(R_{1} \cdot M_{2}\right)}{\pi_{R}}(1-y)=\underset{\left(R_{1} \cdot M_{1}\right)}{\left\{\pi_{R}\right.}-\underset{\left(R_{1} \cdot M_{2}\right)}{\pi_{R}}\right\} y+\underset{\left(R_{1} \cdot M_{2}\right)}{\pi_{R}} .
$$

The expected profit of one retailer choosing the behavior strategy $R_{2}$ under the manufacturer's behavior strategies $M_{1}$ and $M_{2}$ is obtained as

$$
\left.E_{R 2}=\underset{\left(R_{2} \cdot M_{1}\right)}{\pi_{R}} y+\underset{\left(R_{2} \cdot M_{2}\right)}{\pi_{R}}(1-y)=\underset{\left(R_{2} \cdot M_{1}\right)}{\pi_{R}}-\underset{\left(R_{2} \cdot M_{2}\right)}{\pi_{R}}\right\} y+\underset{\left(R_{2} \cdot M_{2}\right)}{\pi_{R}} .
$$

From Eqs. (9) and (10) and Table 2, by considering the adoption ratios of the retailer's population taking $R_{1}$ and $R_{2}, x$ and $(1-x)$, the expected profit of retailer's population is obtained as

$$
\begin{aligned}
\overline{E_{R}}= & x E_{R 1}+(1-x) E_{R 2}=\underset{\left(R_{1} \cdot M_{1}\right)}{\left.\underset{\left(R_{1} \cdot M_{2}\right)}{\pi_{R}}-\underset{\left(R_{2} \cdot M_{1}\right)}{\pi_{R}}+\underset{\left(R_{2} \cdot M_{2}\right)}{\pi_{R}}\right\} x y} \\
& \left.+\underset{\left(R_{1} \cdot M_{2}\right)}{\left.\underset{\left(R_{R}\right.}{\pi_{\left(R_{2} \cdot M_{2}\right)}}-\underset{\left(R_{1} \cdot M_{1}\right)}{\pi_{R}}\right\}} x+\underset{\left(R_{1} \cdot M_{2}\right)}{\pi_{R}}\right\} y+\underset{\left(R_{1} \cdot M_{2}\right)}{\pi_{R} .}
\end{aligned}
$$

Meanwhile, the expected profit of one manufacturer choosing the behavior strategy $M_{1}$ under the retailer's behavior strategies $R_{1}$ and $R_{2}$ is obtained as

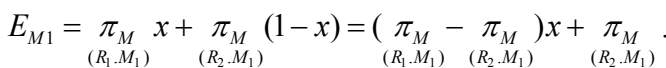

The expected profit of one manufacturer choosing the behavior strategy $M_{2}$ under retailer's behavior strategies $R_{1}$ and $R_{2}$ is obtained as

$$
\left.E_{M 2}=\underset{\left(R_{1} \cdot M_{2}\right)}{\pi_{M}} x+\underset{\left(R_{2} \cdot M_{2}\right)}{\pi_{M}}(1-x)=\underset{\left(R_{1} \cdot M_{2}\right)}{\left\{\pi_{M}\right.}-\underset{\left(R_{2} \cdot M_{2}\right)}{\pi}\right\} x+\underset{\left(R_{2} \cdot M_{2}\right)}{\pi_{M}} .
$$

From Eqs. (12) and (13) and Table 2, by considering the adoption ratios of the manufacturer's population taking $M_{1}$ and $M_{2}, y$ and (1-y), the expected profit of manufacturer's population is obtained as

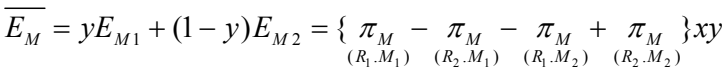

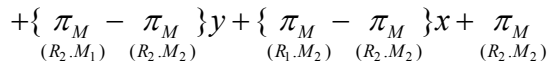

Using the values of $E_{R 1}$ and $\overline{E_{R}}$, the replicator dynamics equation of one retailer can be obtained as

$$
\begin{aligned}
& \dot{x}=\frac{d x}{d t}=x\left(E_{R_{1}}-\overline{E_{R}}\right)=x(1-x)\left(E_{R_{1}}-E_{R_{2}}\right)=x(1-x)
\end{aligned}
$$

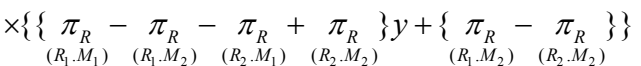

Eq. (15) indicates the time variation of the behavior strategy $R_{1}$ in the retailer's population.

Using the values of $E_{M 1}$ and $\overline{E_{M}}$, the replicator dynamics equation of one manufacturer can be obtained as

$$
\begin{aligned}
& \dot{y}=\frac{d y}{d t}=y\left(E_{M_{1}}-\overline{E_{M}}\right)=y(1-y)\left(E_{M_{1}}-E_{M_{2}}\right)=y(1-y)
\end{aligned}
$$

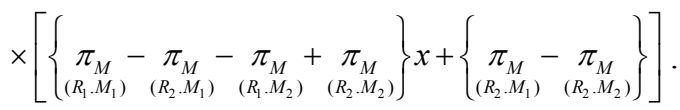

Eq. (16) indicates the time variation of the behavior strategy $M_{1}$ in the manuafcturer's population.

The stable state of the replicator dynamics equation is the equilibrium of the non-linear system (Ellison and Fudenburg, 2000; Zhou and Deng, 2006; Zhu and Dou, 2007; Yu et al., 2009; Barari, et al., 2012). When $\dot{x}=0$ in Eq. (15) and $\dot{y}=0$ in Eq. (16), the following five equilibriums (strategy pairs) are obtained as:

$$
\begin{aligned}
& (x, y)=\left(x_{1}, y_{1}\right),\left(x_{2}, y_{2}\right),\left(x_{3}, y_{3}\right),\left(x_{4}, y_{4}\right),\left(x_{5}, y_{5}\right) \\
& =(0,0),(0,1),(1,0),(1,1) \text {, }
\end{aligned}
$$

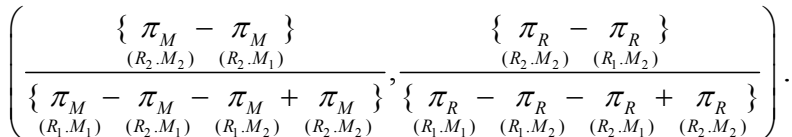

Here, the equilibrium (strategy pair) $\left(x_{5}, y_{5}\right)$ are fractional between 0 and 1 , referred as to the inner points.

When an equilibrium of the replicator dynamics equation is an evolutionary equilibrium, which equals to the locally asymptotically, it is judged as the evolutionary stable strategy (ESS). The standard Jacobian Matrix $(J)$ and Eqs. (15) and (16) are used in order to evaluate the asymptotic stability of an equilibrium strategy pair regarding $x$ and $y$ and obtain the ESS (Friedman, 1999; Ellison and Fudenburg, 2000; Zhou and Deng, 2006; Zhu and Dou, 2007; Yu et al., 2009; Barari, et al., 2012). When the asymptotic stability of an equilibrium strategy pair regarding $x$ and $y$ can be obtained, the asymptotic stability of an equilibrium strategy pair regarding (1-x) and $(1-y)$ can be calculated simultaneously. Therefore, the adoption ratio of the retailer's population taking the behavior strategy $R_{1}, x$, and the adoption ratio of the retailer's population taking the behavior strategy $R_{2}$, (1$x$ ), can be obtained as the ESS. Similarly, the adoption ratio of the manufacturer's population taking the behavior strategy $M_{1}, y$, the adoption ratio of the retailer's population taking the behavior strategy $M_{2},(1-y)$ can be obtained as the ESS.

Five equilibriums in Eq. (17) are judged if they are the ESS, using the following procedures.

\section{[Step 1]}

Using Eqs. (15) and (16), obtain the Jacobian Matrix $J$ as

$$
J=\left[\begin{array}{ll}
\frac{\partial \dot{x}}{\partial x} & \frac{\partial \dot{x}}{\partial y} \\
\frac{\partial \dot{y}}{\partial x} & \frac{\partial \dot{y}}{\partial y}
\end{array}\right]=\left[\begin{array}{ll}
A & B \\
C & D
\end{array}\right],
$$




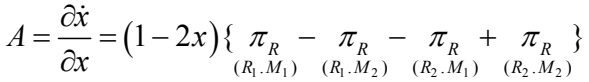

$$
\begin{aligned}
& +(1-2 x)\left\{\pi_{R}-\pi_{R}\right\} \text {, } \\
& B=\frac{\partial \dot{x}}{\partial y}=x(1-x)\left\{\underset{\left(R_{1} \cdot M_{1}\right)}{\pi_{R}}-\underset{\left(R_{1} \cdot M_{2}\right)}{\pi_{R}}-\underset{\left(R_{2} \cdot M_{1}\right)}{\pi_{R}}+\underset{\left(R_{2} \cdot M_{2}\right)}{\pi_{R}}\right\}, \\
& C=\frac{\partial \dot{y}}{\partial x}=\left\{\underset{\left(R_{1} \cdot M_{1}\right)}{\pi_{M}}-\underset{\left(R_{2} \cdot M_{1}\right)}{\pi_{M}}-\underset{\left(R_{1} \cdot M_{2}\right)}{\pi_{M}}+\underset{\left(R_{2} \cdot M_{2}\right)}{\pi_{M}}\right\} y(1-y), \\
& \left.D=\frac{\partial \dot{y}}{\partial y}=(1-2 y) \underset{\left(R_{1} \cdot M_{1}\right)}{\pi_{M}}-\underset{\left(R_{2} \cdot M_{1}\right)}{\pi_{M}}-\underset{\left(R_{1} \cdot M_{2}\right)}{\pi_{M}}+\underset{\left(R_{2} \cdot M_{2}\right)}{\pi_{M}}\right\} x \\
& +(1-2 y)\left\{\pi_{M}-\pi_{M}\right\} \text {. }
\end{aligned}
$$

\section{[Step 2]}

Substitute five equilibriums $\left(x^{j}, y^{j}\right)(j=1,2, \cdots, 5)$ in Eq. (17) into the Jacobian Matrix $J$ in Eqs. (18)-(22).

\section{[Step 3]}

Investigate if five equilibriums (behavior strategy pairs) $\left(x^{j}, y^{j}\right)(j=1,2, \cdots, 5)$ satisfy both conditions: $\operatorname{det}(J)$ $>0$ and $\operatorname{tr}(J)<0$. Here, $\operatorname{det}(J)=\mathrm{AD}-\mathrm{BC}, \operatorname{tr}(J)=\mathrm{A}+\mathrm{D}$. If any equilibrium (behavior strategy pair) $\left(x^{j}, y^{j}\right)$ satisfies both conditions: $\operatorname{det}(J)>0$ and $\operatorname{tr}(J)<0,\left(x^{j}, y^{j}\right)$ is asymptotically stable, and judged as an ESS of the evolutionary game with an non-linear system.

\section{[Step 4]}

If both $B$ and $C$ for $\left(x^{j}, y^{j}\right)(j=1,2, \cdots, 5)$ are 0 in the Jacobian Matrix $J$ in Eqs. (20) and (21), $A$ and $D$ for $\left(x^{j}, y^{j}\right)$ are judged as the eigenvalue. If the conditions: both $A<0$ and $D<0$ for $\left(x^{j}, y^{j}\right)$ are satisfied, $\left(x^{* j}, y^{* j}\right)$ is an asymptotically stable and judged as an ESS.

\section{[Step 5]}

If both $B$ and $C$ for $\left(x^{j}, y^{j}\right)(j=1,2, \cdots, 5)$ are not 0 , obtain the eigenvalue $\lambda$ for $\left(x^{j}, y^{j}\right)(j=1,2, \cdots, 5)$ by solving the following eigen equation for $\left(x^{j}, y^{j}\right)$ :

$$
\begin{aligned}
& \lambda=\left\{(A+D) \pm \sqrt{(A+D)^{2}-4(A D-B C)}\right\} / 2 \\
& (A+D)^{2}-4(A D-B C)>0 .
\end{aligned}
$$

Here, A, B, C and D can be obtained in Eqs. (19)-(22).

If the eigenvalue $\lambda<0$, the equilibrium (behavior strategy pair) $\left(x^{j}, y^{j}\right)(j=1,2, \cdots, 5)$ is the asymptotically stable and judged as the ESS. If the eigenvalue $\lambda>0,\left(x^{j}, y^{j}\right)$ is not the ESS. If the eigenvalue $\lambda=0$, it is impossible to eveluate whether $\left(x^{j}, y^{j}\right)(j=1,2, \cdots$, 5) is the ESS or not.

If the condition

$$
(A+D)^{2}-4(A D-B C)<0
$$

is satisfied for $\left(x^{j}, y^{j}\right)(j=1,2, \cdots, 5)$, the eigenvalue $\lambda$ is the complex number.

In this case, investigate the real part of the eigen- value $\lambda$. If $(A+D)<0,\left(x^{j}, y^{j}\right)(j=1,2, \cdots, 5)$ is the asymptotically stable and judged as the ESS. If the eigenvalue $(A+D)>0,\left(x^{j}, y^{j}\right)$ is not the ESS. If $(A+D)=0$, it is impossible to eveluate whether $\left(x^{j}, y^{j}\right)(j=1,2$, $\cdots, 5)$ is the ESS or not.

\section{NUMERICAL ANALYSIS}

The analysis numerically demonstrates how parameters, related to the recycling promotion activity in a RSC, affect the judgment of the evolutionary stable strategy (ESS) of the behavior strategies of a retailer and a manufacturer in a RSC by using analysis method of the evolutionary game theory proposed in Sections 4 and 5. The initial data sources (system parameters) of the numerical examples in a RSC are provided as follows: $D=200, \alpha_{1}>\alpha_{2}, \beta_{1}>\beta_{2}, \alpha_{1}=1.2, \beta_{1}=1.3, \alpha_{2}$ $=\beta_{2}=1.01, p=150, w=50, A=100, t=3, t_{0}=1, c_{t}=1$, $c_{s p}=(p D) \times 0.05, r=0.3, \mathrm{c}_{\mathrm{r}}=30, c=7, c_{a}=1, c_{d}=1, R=$ 4.5, $R_{0}=1, c_{n}=\mathrm{c}_{\mathrm{r}}+10, c_{s}=(w D) \times 0.05, c_{p}=(p D) \times 0.05$. Especially, this paper focuses on (i) sale promotion cost $c_{s p}$, (ii) monitoring $\operatorname{cost} c_{s}$, (iii) compensation $R$ and (iv) penalty $\operatorname{cost} c_{p}$ as the parameters related to the recycling promotion activity in a RSC. Here, it is necessary to clarify how each of four parameters (i)-(iv) related to the recycling promotion activity affect the evaluation of the ESS for the behavior strategies of a retailer and a manufacturer in the RSC. So, this paper conducts some sensibility analyses by changing each of four parameters (i)(iv) one by one in the feasible ranges for the operation of the RSC where $1 \leq c_{s p} \leq p \alpha_{1} D, 1 \leq c_{s} \leq w \alpha_{1} D, 1 \leq R<2 w$ and $1 \leq c_{p} \leq 3 w \alpha_{1} D$. Step size to change the value of each of four parameters (i)-(iv) is set as 1 of the integer value. The reason why changing each of four parameters (i)(iv) one by one is to bring clarity to the effect of each of parameters (i)-(iv) related to the recycling promotion activity in a RSC on the evaluation of the ESS for the behavior strategy of each member in the RSC.

All data sources sets used as the numerical examples are modifiable if needed.

Figures 1-4 show the effects of parameters (i)-(iv) on the judgment of ESS for the behavior strategies of a retailer and a manufacturer in the RSC.

\section{- Effect of Sales Promotional Cost $c_{s p}$ on ESS}

Figure 2 shows the effect of sales promotion cost $c_{s p}$ on the judgment of the ESSs by using Sections 4 and 5 . In the range where $c_{s p}$ is low, $(x, y)=(1,0)$ is judged as the EES for the behavior strategies of a retailer and a manufacturer in a RSC. This result means that the retailer's population always tends to take the behavior strategy $R_{1}$, meanwhile the manufacturer's population always tends to take the behavior strategy $M_{2}$. From Section 3 and Table 1 , the more the retailer taking $R_{1}$ pays the sales promotion $\operatorname{cost} c_{s p}$, the more the product demand increases at the estimated rate of the product demand $\alpha_{2}$. In the range where $c_{s p}$ is low, $R_{1}$ results in the 


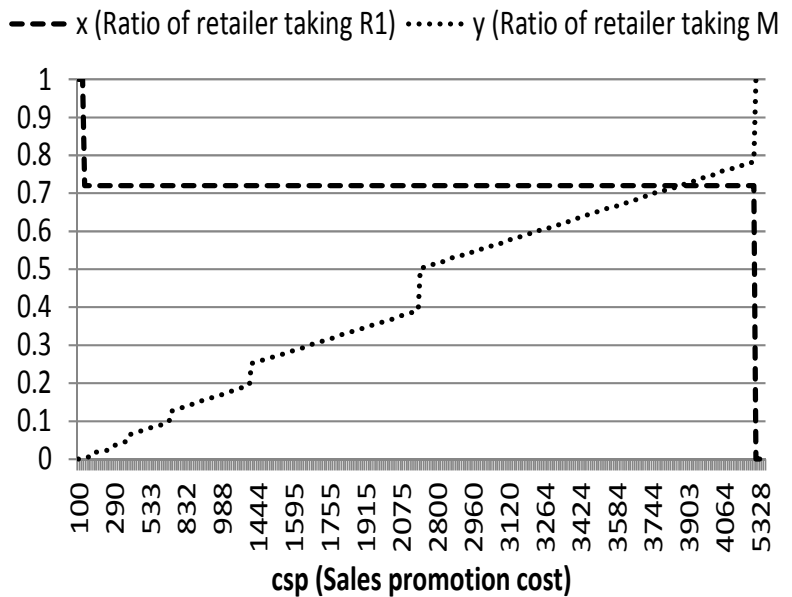

Figure 2. Effect of change of sales promotion $\operatorname{cost} c_{s p}$ on judgment of ESS for members' behavior strategies in a RSC.

increase of the retailer's product sales. The manufacturer can guess the retailer's population tends to take the behavior strategy $R_{1}$ when $c_{s p}$ is low regardless of the manufacturer's act, that is, regardless whether the retailer's act is monitored by the manufacturer or not. Therefore, the manufacturer's population tends to take the behavior strategy $M_{2}$ since the monitoring of the retailer's act is unneeded.

Meanwhile, as $c_{s p}$ becomes higher, it verified that the judgment of the EES for the behavior strategies a retailer and a manufacturer in a RSC are modified from $(x, y)=(1,0)$ to $(x, y)=(0,1)$ by using Sections 4 and 5 . This result means that the retailer's population always tends to take the behavior strategy $R_{2}$, meanwhile the manufacturer's population always tend to take the behavior strategy $M_{1}$. From Section 3 and Table 1, in the range where $c_{s p}$ is high, $R_{2}$ works to be negative to take both the collection promotion of the used products and the sales promotion of the products reusing the recycled parts in order to avoid reducing the retailer's profit. The manufacturer can guess that the retailer's population tends to take the behavior strategy $R_{2}$ as $c_{s p}$ becomes higher regardless of the manufacturer's act. Therefore, the manufacturer's population tends to take the behavior strategy $M_{1}$ since the monitoring of the retailer's act is needed.

\section{- Effect of Monitoring Cost $c_{s}$ on ESS}

Figure 3 shows the effect of monitoring $\cos t c_{s}$ on the judgment of the ESSs by using Sections 4 and 5. In the range where $c_{S}$ is low, $(x, y)=(1,1)$ is judged as the EES for the behavior strategies of a retailer and a manufacturer in a RSC. This result means that the retailer's population always tends to take the behavior strategy $R_{1}$, meanwhile the manufacturer's population always tends to take the behavior strategy $M_{1}$. From Section 3 and Table 1, when the manufacturer monitors the retailer's act at the monitoring $\cos t c_{s}$, the correct increasing rate of the product demand can be known. Besides, the more

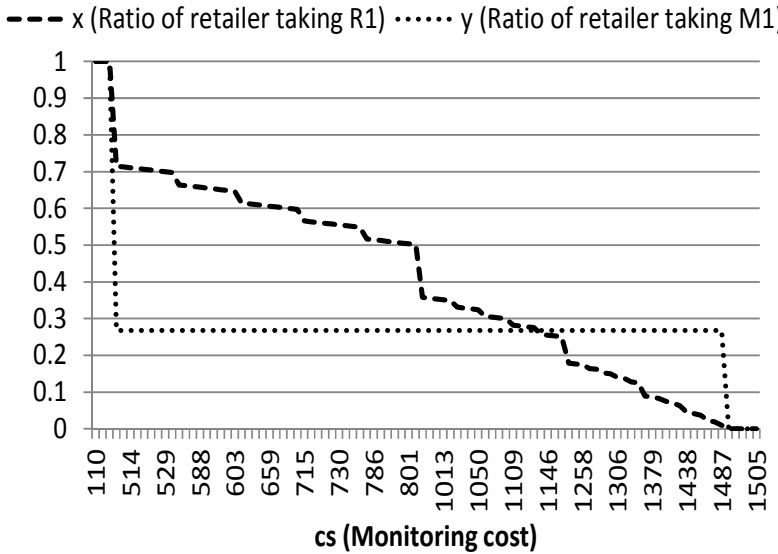

Figure 3. ffect of change of monitoring $\operatorname{cost} c_{s}$ on judgment of ESS for members' behavior strategies in a RSC.

the retailer taking $R_{1}$ pays the sales promotion cost $c_{s p}$, the more the product demand increases at the correct rate $\alpha_{1}$ by the manufacturer's monitoring. In the range where $c_{s}$ is low, $\left(R_{1}, M_{1}\right)$ can bring the more profits to both members in the RSC since $\alpha_{1}>\alpha_{2}, \beta_{1}>\beta_{2}$ and the increment of the manufacturer's wholesales of products outgoes his/her total cost related to the part recycled from the used products.

Meanwhile, as $c_{s}$ becomes higher, it verified that the judgment of the EES for the behavior strategies of a retailer and a manufacturer in a RSC are modified from $(x, y)=(1,1)$ to $(x, y)=(0,0)$ by using Sections 4 and 5 . This result means that the retailer's population always tends to take the behavior strategy $R_{2}$, meanwhile the manufacturer's population always tends to take the behavior strategy $M_{2}$. From Section 3 and Table 1, in the range where $c_{s}$ is high, $M_{2}$ works to be negative to monitor the retailer's act regarding the collection promotion of the used products and the sales promotion of the products reusing the recycled parts in order to avoid reducing the manufacturer's profit. The retailer can guess that the manufacturer's population tends to take the behavior strategy $M_{2}$ as $c_{s}$ becomes higher regardless of the retailer's act. Therefore, the retailer's population tends to take the behavior strategy $R_{2}$. This is because it is unnecessary for the retailer to pay the penalty cost to the manufacturer, although compensation income from the manufacturer in $R_{2}$ is lower than that in $R_{1}$.

\section{- Effect of Compensation $R$ on ESS}

Figure 4 shows the effect of compensation $R$ on the judgment of the ESSs by using Sections 4 and 5 . In the range where $R$ is low, the inner points $\left(x_{5}, y_{5}\right)$ obtained in equation (17) is judged as the EES for the behavior strategies of a retailer and a manufacturer in a RSC. When $R$ is low, it is shown that the adoption ratio of retailer's population taking $R_{1}, x$, tends to be higher than that taking $R_{2}, 1-x$, meanwhile the adoption ratio of manufacturer's population taking $M_{1}, y$, tends to be lower 


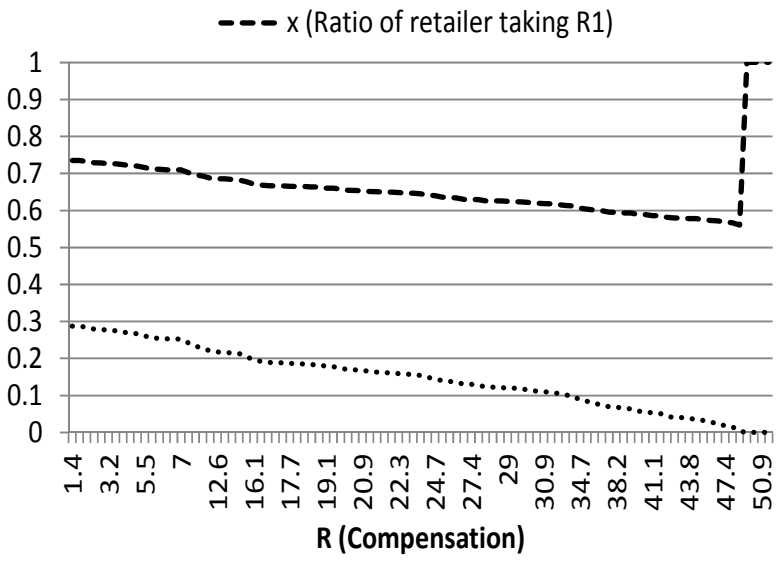

Figure 4. Effect of change of compensation $R$ on judgment of ESS members' behavior strategies in a RSC.

than that taking $M_{2}, 1-y$. It verifies that both members are modifying their own behavior strategies considering the profit balance between both members by using the equilibrium $\left(x_{5}, y_{5}\right)$ in equation (17) and analyzing the Jacobian Matrix $J$ with the evolutionary dynamics in equations (18)-(22).

Meanwhile, as $R$ is higher, it verifies that the judgment of the EES for the behavior strategies in the RSC are modified to $(x, y)=(1,0)$ by using Sections 4 and 5 . This result means that the retailer's population always tends to take the behavior strategy $R_{1}$, meanwhile the manufacturer's population always tends to take the behavior strategy $M_{2}$. From Section 3 and Table 1, the more the retailer taking $R_{1}$ pays the sales promotion cost $c_{s p}$, the more the compensation income from the manufacturer increases. The manufacturer can guess thar the retailer's population tends to take the behavior strategy $R_{1}$ when $R$ is high regardless of the manufacturer's act. Therefore, the manufacturer's population tends to take the behavior strategy $M_{2}$ since the monitoring of the retailer's act is unneeded.

\section{- Effect of Penalty Cost $c_{p}$ on ESS}

Figure 5 shows the effect of penalty $\operatorname{cost} c_{p}$ on the judgment of the ESSs by using Sections 4 and 5 . In the range where $c_{p}$ is low, $(x, y)=(0,0)$ is judged as the EES for the behavior strategies of a retailer and a manufacturer in a RSC. This result means that the retailer's population always tends to take the behavior strategy $R_{2}$, meanwhile the manufacturer's population always tends to take the behavior strategy $M_{2}$. From Eqs. (2) and (6), a manufacturer determines the own behavior strategy from the magnitude relation between the monitoring $\operatorname{cost} c_{s}$ and the penalty income $c_{p}$ from a retailer. Meanwhile, from Eqs. (1) and (5), a retailer determines the own behavior strategy from the magnitude relation between the sales promotion $\cos t c_{s p}$ and the penalty cost $c_{p}$ to a manufacturer.

Meanwhile, as $c_{p}$ becomes higher, the judgment of the EES for the behavior strategies of members in the RSC

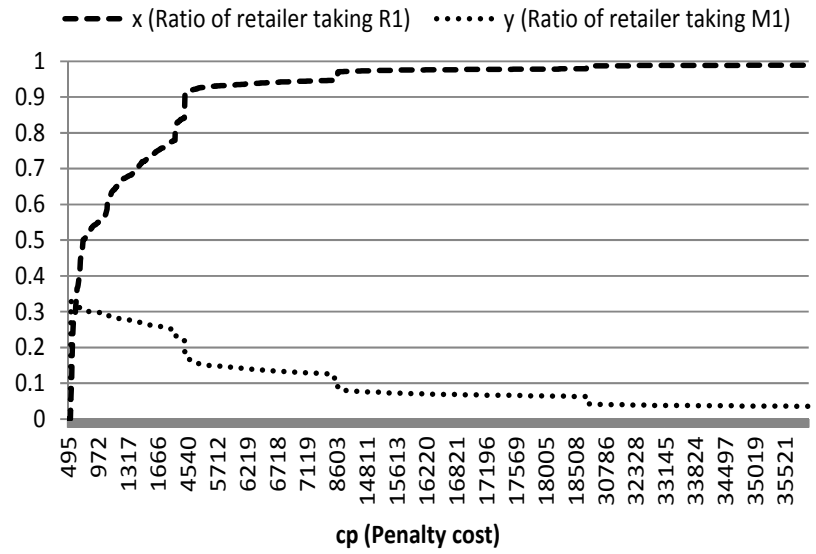

Figure 5. Effect of change of penalty $\operatorname{cost} c_{p}$ on judgment of ESS members' behavior strategies in a RSC.

tends to be modified from $(x, y)=(0,0)$ to around $(x, y)$ $=(1,0)$ by using Sections 4 and 5 . This result means that the retailer's population always tends to take the behavior strategy $R_{1}$, meanwhile the manufacturer's population always tends to take the behavior strategy $M_{2}$. From Section 3 and Table 1, the more the retailer taking $R_{1}$ pays the sales promotion $\operatorname{cost} c_{s p}$, not only the less the retailer who needs to pay the penalty to the manufacturer, but also the more the product demand increases at the estimated rate of the product demand $\alpha_{2}$. In the range where $c_{p}$ is high, $R_{1}$ results in the increase of the retailer's product sales. The manufacturer can guess that the retailer's population tends to take the behavior strategy $R_{1}$ as $R$ becomes higher regardless of the manufacturer's act. Therefore, the manufacturer's population tends to take the behavior strategy $M_{2}$ since the monitoring of the retailer's act is unneeded.

\section{CONCLUSIONS}

This paper discussed a reverse supply chain (RSC) which consisted of a retailer and a manufacturer as RSC members and verified analytically the behavior strategies of RSC members which might change over time in response to changes system parameters related to the recycling promotion activity in the RSC by using the evolutionary game theory based on the replicator dynamics mechanism. Concretely, a retailer chose two behavior strategies: cooperation or non-cooperation in the recycling promotion activity in a RSC. A manufacturer chose two behavior strategies: monitoring or nonmonitoring of the behavior of the retailer. This paper focused on the following parameters related to the recycling promotion activity in a RSC: (i) sale promotion cost, (ii) monitoring cost, (iii) compensation and (iv) penalty cost. The evolutionary game theory was adopted to analyze the evolutionary outcomes driven by changes in members' behaviors in a RSC over time. The evolutionary stable strategies (ESSs) for members' behaviors 
in a RSC were derived by using the replicator dynamics mechanism. The analysis numerically investigated how four parameters (i)-(vi) affected the judgment of the ESSs for members' behavior strategies in the RSC. The different ESSs for members' behavior strategies in the RSC were analyzed by changing each of four parameters (i)-(iv) one by one in those parameters' feasible ranges for the operation of the RSC.

From the research outcomes in this paper, members' behavior strategies in a RSC were provided analytically by using the evolutionary game theory, which combined the evolutionary theory by Darwin based on the replicator dynamics mechanism with the game theory. The analytical outcomes can help to verify members' behavior strategies in a RSC even if their behavior strategies in the RSC may change over time due to changes of members' situations in a RSC such as cost parameters and the quantities of their transactions. Also, the analytical results provided (1) the optimal setting of parameters related to the recycling promotion activity in a RSC such as (i) sale promotion cost, (ii) monitoring cost, (iii) compensation and (iv) penalty cost, (2) the practices to construct and operate a RSC profitably and (3) the informative motivations for researchers and policymakers to manage a RSC.

This paper can show the following managerial insights from outcomes obtained from both the theoretical research and the numerical analysis to not only academic researchers, but also real-world policymakers regarding operations in a RSC:

(1) Presentation of analytical results for a RSC by using the evolutionary game theory based on the replicator dynamics mechanism, referred to the evolutionary dynamics, and presentation of the evolutionary stable strategies (EESs) for behavior strategy of members in the RSC,

(2) Presentation of analytical results for a RSC for the cooperation of the recycling promotion activity in a RSC by using the concepts of compensation and penalty between members in the RSC,

(3) Presentation of analytical results for the effect of the recycling promotion activity in a RSC on the collection quantity of used products and the product demand,

(4) Presentation of both elicitation process of formulations and analysis of the evolutionary dynamics by using costs and profits of members related to the recycling promotion activity in a RSC with mathematical expressions.

Thus, it is expected that research outcomes in this paper enable to link strongly to analysis of members' behavior strategies in a RSC and the RSC's operational management. Therefore, the contribution of this paper can provide not only informative motivations, but also one of the optimal solutions to construct a RSC profitably for researchers and policymakers regarding not only inventory management, but also supply chain coordina- tion in a RSC, considering behavior strategies of members in a RSC.

As future researches, it will be necessary to extend the following topics into the evolutional stable analysis of a RSC in this paper: (i) the optimal decisions for the operation in a RSC with the evolutionary dynamics and (ii) analysis of the evolutionary dynamics with more than three either behavior strategies or members in a RSC.

\section{ACKNOWLEDGMENT}

This research has been supported by the Grant-inAid for Scientific Research C No. 25350451 from the Japan Society for the Promotion of Science.

\section{REFERENCES}

Aras, N., Boyaci, T., and Verter, V. (2004), The effect of categorizing returned products in remanufacturing, IIE Transactions, 36(4), 319-331.

Aust, G. and Buscher, U. (2012), Vertical cooperative advertising and pricing decisions in a manufacturer-retailer supply chain: a game-theoretic approach, European Journal of Operational Research, 223(2), 473-482.

Bakal, I. S. and Akcali, E. (2006), Effects of random yield in remanufacturing with price-sensitive supply and demand, Production and Operations Management, 15(3), 407-420.

Barari, S., Agarwal, G., Zhang, W. J. (Chiris), Mahanty, B., and Tiwari, M. K. (2012), A Decision Framework for the Analysis of Green Supply Chain Contracts: An Evolutionary Game Approach, Expert Systems with Applications, 39(3), 2965-2976.

Behret, H. and Korugan, A. (2009), Performance analysis of a hybrid system under quality impact of returns, Computers and Industrial Engineering, 56(2), 507-520.

Berr, F. (2011), Stackelberg equilibria in managerial delegation games, European Journal of Operational Research, 212(2), 251-262.

Cachon, G. P. and Netessine, S. (2004), Game theory in supply chain analysis. In: Simchi-Levi, D., Wu, S. D., and Shen, Z. J. (eds.), Handbook of Quantitative Supply Chain Analysis: Modeling in the e-Business Era, Kluwer, Boston, MA, 13-65.

Cai, G. G., Zhang, Z. G., and Zhang, M. (2009), Game theoretical perspectives on dual-channel supply chain competition with price discounts and pricing schemes, International Journal of Production Economics, 117(1), 80-96.

Du, J., Liang, L., Chen, Y., Cook, W. D., and Zhu, J. 
(2011), A bargaining game model for measuring performance of two-stage network structures, European Journal of Operational Research, 210(2), 390-397.

Guide, D. V. R., JR. and Jayaraman, V. (2000), Product acquisition management: current industry practice and a proposed framework, International Journal of Production Research, 38(16), 3779-3800.

Ellison, G. and Fudenburg, D. (2000), Leaning Purified Mixed Equilibria, Journal of Economic Theory, 90, $84-115$.

Esmaeili, M. and Zeephongsekul, P. (2010), Sellerbuyer models of supply chain management with an asymmetric information structure, International Journal of Production Economics, 123(1), 146-154.

Ferguson, M., Guide, V. D., Koca, E., and Souza, G. C. (2009), The value of quality grading in remanufacturing, Production and Operations Management, 18(3), 300-314.

Fleischmann, M., Bloemhof-Ruwaard, J. M., Dekker, R., Van der Laan, E., Van Nunen, J. A., and Van Wassenhove, L. N. (1997), Quantitative models for reverse logistics: a review, European Journal of Operational Research, 103(1), 1-17.

Friedman, D. (1991) Evolutionary Games in Economics, Econometrica, 59(3), 637-666.

Guide, V. D. R., JR. (2000), Production Planning and Control for Remanufacturing: Industry Practice and Research Needs, Journal of Operation Management, 18(4), 467-483.

Guide, V. D. R. and Wassenhove, L. N. (2001), Managing product returns for remanufacturing, Production and Operations Management, 10(2), 142-155.

Guide, V. D. R., Teunter, R. H., and Van Wassenhove, L. N. (2003), Matching demand and supply to maximize profits from remanufacturing, Manufacturing and Service Operations Management, 5(4), 303-316.

Hu, Y., Guan, Y., and Liu, T. (2011), Lead-time hedging and coordination between manufacturing and sales departments using Nash and Stackelberg games, European Journal of Operational Research, 210(2), 231-240.

Inderfurth, K. (2005), Impact of uncertainties on recovery behavior in a remanufacturing environment: a numerical analysis, International Journal of Physical Distribution and Logistics Management, 35(5), 318-336.

Kaya, O. (2010), Incentive and production decisions for remanufacturing operations, European Journal of Operational Research, 201(2), 442-453.

Konstantaras, I., Skouri, K., and Jaber, M. Y. (2010), Lot sizing for a recoverable product with inspection and sorting, Computers and Industrial Engineering, 58(3), 452-462.
Lee, C., Realff, M., and Ammons, J. (2011), Integration of channel decisions in a decentralized reverse production system with retailer collection under deterministic non-stationary demands, Advanced Engineering Informatics, 25(1), 88-102.

Leng, M. and Parlar, M. (2009), Lead-time reduction in a two-level supply chain: Non-cooperative equilibria vs. coordination with a profit-sharing contract, International Journal of Production Economics, 118 (2), 521-544.

Liu, Z. L., Anderson, T. D., and Cruz, J. M. (2012), Consumer environmental awareness and competition in two-stage supply chains, European Journal of Operational Research, 218(3), 602-613.

Maynard-Smith, J. (1974), The Theory of Games and the Evolution of Animal Conflicts, Journal of Theoretical Biology, 47(1), 209-221.

Mukhopadhyay, S. K. and Ma, H. (2009), Joint procurement and production decisions in remanufacturing under quality and demand uncertainty, International Journal of Production Economics, 120(1), 5-17.

Mukhopadhyay, S. K., Yue, X., and Zhu, X. (2011), A Stackelberg model of pricing of complementary goods under information asymmetry, International Journal of Production Economics, 134(2), 424-433.

Nenes, G., Panagiotidou, S., and Dekker, R. (2010), Inventory control policies for inspection and remanufacturing of returns: a case study, International Journal of Production Economics, 125(2), 300-312.

Pokharel, S. and Liang, Y. (2012), A model to evaluate acquisition price and quantity of used products for remanufacturing, International Journal of Production Economics, 138(1), 170-176.

Shi, J., Zhang, G., Sha, J., and Amin, S. H. (2010), Coordinating production and recycling decisions with stochastic demand and return, Journal of Systems Science and Systems Engineering, 19(4), 385-407.

Shi, J., Zhang, G., and Sha, J. (2011), Optimal production planning for a multi-product closed loop system with uncertain demand and return, Computers \& Operations Research, 38(3), 641-650.

Tagaras, G. and Zikopoulos, C. (2008), Optimal location and value of timely sorting of used items in a remanufacturing supply chain with multiple collection sites, International Journal of Production Economics, 115(2), 424-432.

Taylor, P. J. and Jonker, L. (1978), Evolutionary Stable Strategies and Game Dynamics, Mathematical Bioscience, 40(1/2), 145-156.

Teunter, R. H. and Flapper, S. D. P. (2011), Optimal core acquisition and remanufacturing policies under uncertain core quality fractions, European Journal of Operational Research, 210(2), 241-248.

Thierry, M. C., Salomon, M., van Nunen, J. A. E. E., and 
van Wassenhove, L. N. (1995), Strategic issues in product recovery management, California Management Review, 37(2), 114-135.

Tsay, A. A., Nahmias, S., and Agrawal, N. (1999), Modelling supply chain contracts: a review. In: Tayur, S., Ganeshan, R., and Magazine, M. (eds.), Quantitative Models for Supply Chain Management, Kluwer Academic Publishers, Boston, MA, 299336.

Van Wassenhove, L. N. and Zikopoulos, C. (2010), On the effect of quality overestimation in remanufacturing, International Journal of Production Research, 48(18), 5263-5280.

Watanabe, T., Kusuawa, E., and Arizono, I. (2013), Optimal operation for green supply chain in consideration of collection incentive and quality for recycling of used products, Industrial Engineering and Management Systems, 12(4), 317-329.

Watanabe, T. and Kusukawa, E. (2014), Optimal Operation for Green Supply Chain Considering Demand Information, Collection Incentive and Quality of Recycling Parts, An International Journal of Industrial Engineering and Management Systems, 13, 129-147.

Wei, C., Li, Y., and Cai, X. (2011), Robust optimal policies of production and inventory with uncertain returns and demand, International Journal of Production Economics, 134(2), 357-367.

Wei, J., Zhao, J., and Li, Y. (2012), Pricing decisions for a closed-loop supply chain in a fuzzy environment, Asia-Pacific Journal of Operational Research, 29 (1), 1240003

Wu, C. H. (2012), Product-design and pricing strategies with remanufacturing, European Journal of Operational Research, 222(2), 204-215.

Xiao, T. and Chen, G. (2009), Wholesale pricing and evolutionarily stable strategies od retailers with imperfectly observable objective, European Journal of Operational Research, 196(3), 1190-1201.

Xu, J., Jiang, W., Feng, G., and Tian, J. (2012), Comparing improvement strategies for inventory inaccuracy in a two-echelon supply chain, European Journal of Operational Research, 221(1), 213-221.

Yan, N. N. and Sun, B. W. (2012), Optimal Stackelberg strategies for closed-loop supply chain with thirdparty reverse logistics, Asia-Pacific Journal of Operational Research, 29(5), 1250026.

Yano, C. A. and Gilbert, S. M. (2004), Coordinated pricing and production/procurement decisions: a review. In: Chakravarty, A. K. and Eliashberg, J. (eds.), Managing Business Interfaces, Springer, New York, NY, 65-103.

Yu, H., Zeng, A. Z. and Zhao, L. (2009), Analyzing the Evolutionary Stability of the Vendor-Managed Inventory Supply Chains, Computers and Industrial Engineering, 56(1), 274-282.

Zhou, M. and Deng, F. Q. (2006), Evolutionary Dynamics of an Asymmetric Game Between a Supplier and a Retailer. In: Jiao, L., Wang, L., Gao, X., Liu, J. and $W u, F .(e d s)$, Advances in Natural Computation: Lecture Notes in Computer Science, Springer-Verlag, Heidelberg, Berlin, 4222, 466-469.

Zhu, Q. H. and Dou, Y. J. (2007), Evolutionary Game Model between Governments and Core Enterprises in Greening Supply Chains, Systems EngineeringTheory and Practice, 27(12), 85-89.

Zikopoulos, C. and Tagaras, G. (2007), Impact of uncertainty in the quality of returns on the profitability of a single-period refurbishing operation, European Journal of Operational Research, 182(1), 205-225.

Zikopoulos, C. and Tagaras, G. (2008), On the attractiveness of sorting before disassembly in remanufacturing, IIE Transactions, 40(3), 313-323. 